\title{
Stable patterns of upper limb muscle activation in different conditions of human walking
}

\author{
JOHANN P. KUHTZ-BUSCHBECK | ANTONIA FRENDEL |
}

Institute of Physiology, Christian Albrechts Universität zu Kiel, Kiel, GERMANY.

Correspondence to: Johann P. Kuhtz-Buschbeck, Olshausenstraße 40, D 24098, Kiel, GERMANY.

email: kuhtz@physiologie.uni-kiel.de

\begin{abstract}
AT A GLANCE
We analyze temporal patterns of arm and shoulder muscle activity in conditions of human walking that have not been studied previously (load carriage, arm immobilization). Factor analysis is applied to extract basic temporal muscle activation components. Common activation patterns are identified that remain stable across gait conditions and therefore reflect superordinate motor control strategies.
\end{abstract}

$\begin{array}{ll}\text { ABBREVIATIONS } \\ \text { AD } & \text { anterior deltoid muscle } \\ \text { BIC } & \text { biceps brachii } \\ \text { EMG } & \text { electromyographic } \\ \text { ES } & \text { erector spinae muscle } \\ \text { LD } & \text { latissimus dorsi } \\ \text { MVC } & \text { maximum voluntary contraction } \\ \text { PD } & \text { posterior deltoid muscle } \\ \text { TRAP } & \text { trapezius muscle } \\ \text { TRI } & \text { triceps brachii }\end{array}$

PUBLICATION DATA

Received 17 Nov 2014

Accepted 16 Feb 2015

Published 17 Feb 2015

\begin{abstract}
BACKGROUND: Arm swing during human gait is associated with contractions of upper limb muscles, which rarely have been examined.

AIM: This study aims to identify basic temporal patterns of upper limb muscle activation during walking conditions involving different modes of arm swing.

METHOD: Twenty volunteers were examined during (a) normal forward walking, (b) walking with immobilized arms, (c) walking while carrying loads in one or in both hands. Electromyographic (EMG) data were collected for the trapezius (TRAP), anterior (AD) and posterior deltoid (PD), biceps (BIC), triceps (TRI), latissimus dorsi (LD) and lumbar erector spinae (ES) muscles.

RESULTS: Principal components analyses identified two basic patterns of muscle activation that remained stable across gait conditions. Some rhythmical EMG signals of arm and shoulder muscles (TRAP, PD, TRI, LD) persisted during walking with immobilized arms, indicating coupled activation of leg and arm muscles. Carrying a load in one hand resulted in stronger ipsilateral EMG activity (TRAP, AD, PD, BIC, TRI) than splitting the same load between both hands.

CONCLUSION: Although the amount of upper limb muscle activity varies markedly between different conditions of human walking (with/without arm sing; with/without load carriage), basic temporal activation patterns remain stable, indicating a common motor control strategy.
\end{abstract}

KEYWORDS: arm swing | human gait | muscle activity | upper limb | physiology

\section{INTRODUCTION}

Reciprocal arm swing is a typical feature of human walking, which minimizes ground reaction moments about the vertical axis and reduces energy consumption. ${ }^{1,2} \mathrm{Arm}$ swing is partly induced passively by rhythmical movements of the shoulder girdle.3,4 However, an active contribution of arm and shoulder muscles to arm swing is evident from studies of electromyographic (EMG) activity, which demonstrated rhythmical shortening and lengthening contractions of these muscles during human walking.,5,6

The present EMG study aims to identify basic temporal patterns of upper limb muscle activation in gait conditions with different modes of arm swing. We collected EMG signals during treadmill walking with natural arm swing (baseline), walking with immobilized arms, and during walking while carrying a load. Distribution of a few basic temporal excitation patterns to multiple muscles (i.e. pools of motor neurons) is an efficient control strategy for the performance of multi-segment movements such as locomotion. ${ }^{7}$ Neural control is simplified by the use of excitation patterns that activate synergistic muscles conjointly in different locomotor tasks, and which may be adapted to the specific task demands. ${ }^{8}$ Previous research of muscle activity during human locomotion indicates that

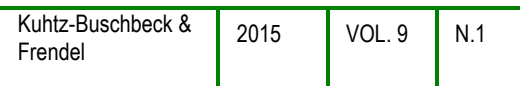


basic EMG components, which characterize common activation patterns of multiple muscles, have indeed waveforms that are relatively conserved across different locomotor tasks and also across different individuals. 8,9 We therefore hypothesized that different gait conditions, which involve dissimilar kinematics of arm swing and different loads, may nevertheless share similar basic temporal EMG activation patterns of upper limb muscles. Principal component analyses (PCA) were performed to detect such common patterns of upper limb motor control. We furthermore compared the amount of muscle activity across different gait conditions.

\section{METHODS}

\section{Participants}

Twenty healthy volunteers (10 women) participated in the experiments (mean age 26 years 2 months, SD 7 years). Their average body height was $178 \pm 8 \mathrm{~cm}$ and their weight $71 \pm 11 \mathrm{~kg}$ (mean $\pm \mathrm{SD}$ ). Exclusion criteria were any neurological or orthopedic pathology affecting gait and/or balance or any apparent gait abnormality. Most participants were college students or staff members of the university. All were familiar with treadmill walking. They wore tank tops, sweatpants and their personal running shoes during the experiments. All volunteers gave informed written consent for participation and publication prior to the experiments. The Ethical Committee of the Medical Faculty of Christian Albrechts University (Kiel, Germany) approved these experimental procedures.

\section{Apparatus and Task}

A treadmill (Woodway®, Weil am Rhein, Germany) with a horizontal belt surface of $162 \mathrm{~cm}$ length and $44 \mathrm{~cm}$ width was used. The handrails were set $1 \mathrm{~m}$ apart so that arm swing was not obstructed. Initially the gait conditions were practiced (Figure 1). They comprised of a) normal walking with free arm swing (baseline); b) walking with both arms immobilized by a brace and Velcro straps that attached the upper arms, forearms and hands to the trunk (medi Armfix® shoulder immobilization support, Bayreuth, Germany). Both arms were supported by the brace, and the participants were asked to relax their upper limb muscles in this condition. c, d) unimanual load carriage, namely walking while carrying a load (dumbbell, $10 \%$ of body weight) in the right hand, or in the left hand; e) bimanual load carriage, i.e. walking with the same load distributed evenly between both hands ( $2 \times 5 \%$ of body weight).

EMG signals of each participant were recorded continuously for about one minute in each gait condition. The order of the conditions was counterbalanced across participants. Stance and swing phases of the right leg (foot contacts) were documented with optical sensors mounted on the treadmill (Optogait@ virtual footswitch, Bolzano, Italy). All gait trials were videotaped. In case of irregularities (e.g. stumbling, hand gestures), the respective gait trial was repeated. The treadmill velocity was always $6 \mathrm{~km} / \mathrm{h}$. 


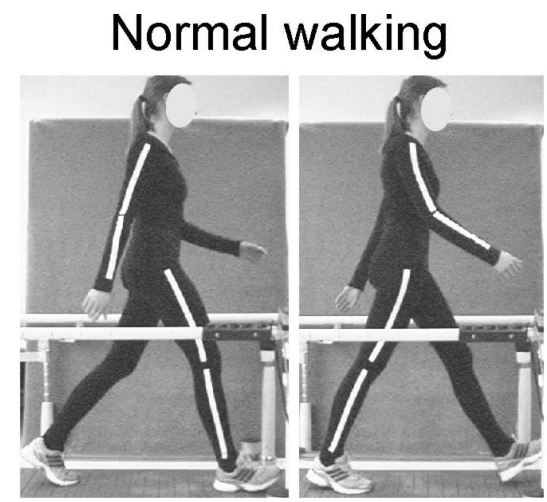

\section{Unilateral load}

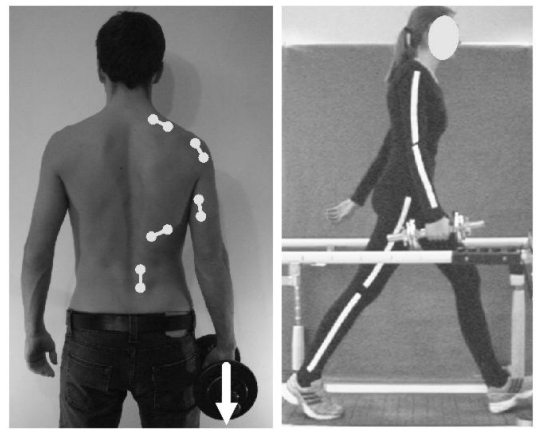

Arm immobilization

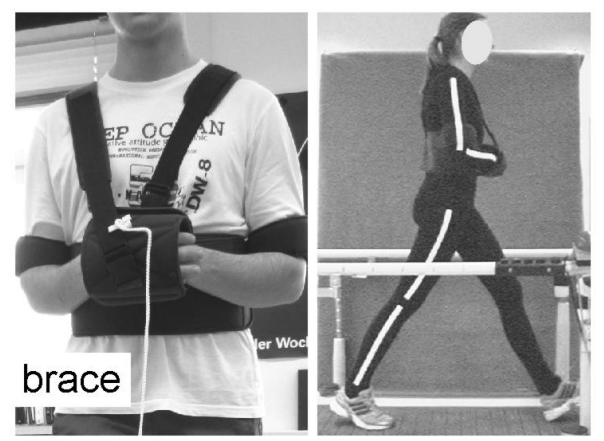

Bilateral load

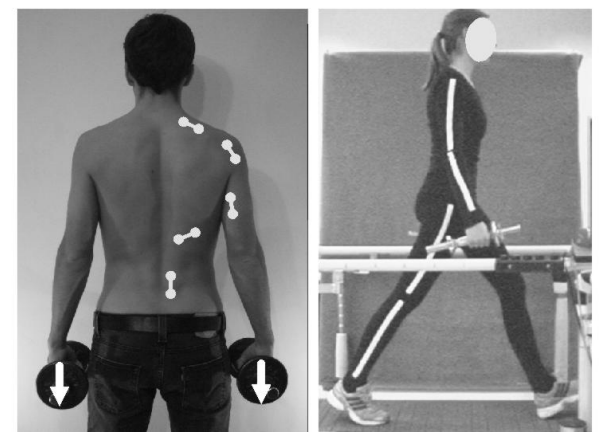

Figure 1. Gait conditions involving different modes of arm swing. Normal walking $(6 \mathrm{~km} / \mathrm{h})$ with unrestricted reciprocal arm swing. Images show onset and end of gait cycle. Arm immobilization: Shoulder and elbow movements are prevented by a brace. Unilateral load carriage: One hand carries a load (10 \% of body weight) during walking. Bilateral load carriage: each hand carries half of the load ( $2 \times 5 \%$ of body weight). The EMG electrode positions above right TRAP, PD, TRI, LD, ES muscles are indicated; BIC and AD electrodes are not visible from the back.

\section{Instrumentation}

EMG electrode placement followed published guidelines. ${ }^{10}$ Disposable $\mathrm{Ag}-\mathrm{AgCl}$ electrodes (Arbo® H124SG, Germany) with a pick-up diameter of $15 \mathrm{~mm}$ were attached to the abraded skin above seven muscles on the right side of the body. A bipolar configuration with an inter-electrode distance of $\sim 2.5 \mathrm{~cm}$ was used. We examined the following muscles: Upper trapezius muscle (TRAP), with electrodes placed on the center of a line connecting vertebra $\mathrm{C} 7$ spinous process and acromion. Anterior deltoid (AD) and posterior deltoid (PD) muscle: electrodes about $4 \mathrm{~cm}$ anterior to acromion on line to thumb $(A D)$; and about $4 \mathrm{~cm}$ posterior to acromion on line to little finger (PD). Biceps brachii (BIC): electrodes between acromion and fossa cubiti on muscle belly. Triceps brachii (TRI): electrodes on long head of the TRI, about $3 \mathrm{~cm}$ medial to a line connecting olecranon and acromion. Latissimus dorsi (LD): Electrodes caudal of inferior scapular angle, oriented parallel to muscle fibers. Lumbar erector spinae (ES): Electrodes positioned about $3 \mathrm{~cm}$ lateral of vertebra $\mathrm{L} 3$ spinous process. The electrode positions are schematically illustrated in Figure 1.

Maximum voluntary contractions (MVC; duration $\sim 3$ seconds) were performed with each relevant muscle for later normalization of the EMG amplitudes. ${ }^{11}$ The TRAP was tested by abducting the extended arm in the frontal plane. Anterior and posterior deltoid muscles ( $A D, P D)$ and $L D$ were tested by vigorous flexion/extension of the shoulder 
against fixed resistance, with the elbow extended. TRI and BIC contracted maximally against resistance, with the elbow flexed by $\sim 90^{\circ}$. To test the paravertebral erector spinae (ES), the participants lay prone and then extended the trunk forcefully against resistance.

The EMG electrodes were connected via pre-amplified electrode leads to an eightchannel Myosystem 1400 L (Noraxon ${ }^{2}$, Scottsdale, AZ, USA) electromyographic system with the following specifications: differential amplifier, input impedance $>100 \mathrm{MOhm}$, common mode rejection ratio $>100 \mathrm{~dB}$ at $60 \mathrm{~Hz}$, sensitivity $1 \mu \mathrm{V}$, baseline noise $<1 \mu \mathrm{V}$ RMS, bandwidth $10-500 \mathrm{~Hz}$. EMG signals were sampled at a rate of $1000 \mathrm{~Hz}$ per channel and $A / D$ converted with a digital 12 bit resolution per channel. They were stored together with video and footswitch data for later offline processing using Noraxon® software (Myo Research XP, Master Edition 1.07).

\section{Data Analysis}

The EMG signals of each muscle were full-wave rectified and smoothed with a root mean square window of $50 \mathrm{~ms}$. Data of $\sim 50$ gait cycles (i.e. one minute of walking) in each participant and gait condition were averaged to obtain representative individual EMG curves. As a common time frame, the gait cycle of the right leg (ipsilateral to the muscles investigated) was time-normalized from $1 \%$ (onset of stance phase, heel strike) to $100 \%$ (end of swing phase). For each gait condition, the EMG data of each muscle were divided by their mean value, as measured in the respective condition. The resulting EMG curves all have an average activity of 1 , across all conditions and muscles. Ensemble averaged EMG curves (group results) of the different conditions were calculated and superimposed (Figure 2) to illustrate activation waveforms that are similar across conditions.

We applied principal components analyses (PCA) to the ensemble averaged EMG curves, i.e. to one matrix $(m \times t)$ per condition, with $m=7$ (number of muscles) and $t=100$ (normalized 100-point time base of gait cycle). From EMG waveforms of a larger number of muscles, PCA extracts a smaller number of underlying basic temporal activation components (factor scores), which account for most of the total variance of the original data set. ${ }^{12,13}$ The statistics software SPSS IBM version 17 (New York, USA) was used; module data reduction/factor analysis/extraction of principal components. The steps include calculation of the correlation matrix, extraction of the initial principal components, computation of eigenvalues, varimax rotation of the factors, calculation of the factor scores (basic temporal components) and factor loadings (weighting coefficients). The factor loadings indicate how a given factor score is distributed to the different muscles. ${ }^{13} \mathrm{We}$ retained factor scores with eigenvalues greater than unity. Correlations between the factor scores of the different gait conditions were analyzed by calculating Pearson's correlation coefficients ( $r$ ).

To assess the overall level of muscle activity, EMG signals of each muscle were amplitude-normalized (unit \% MVC) to the highest amplitude measured in the set of maximum voluntary contractions. Such normalization to MVC values accounts for variations of the EMG voltages between different muscles and different individuals ${ }^{11}$, which can be due to variations in skin conductance, muscle anatomy, sweating rate etc. Mean amplitudes of the MVC-normalized EMG signals were calculated for each participant and condition. To detect (within-subject) differences in mean EMG amplitudes between conditions, analyses of variance followed by paired t-tests were applied (significance level $p<0.05)$. Data of men and women were compared with t-tests for independent samples. 


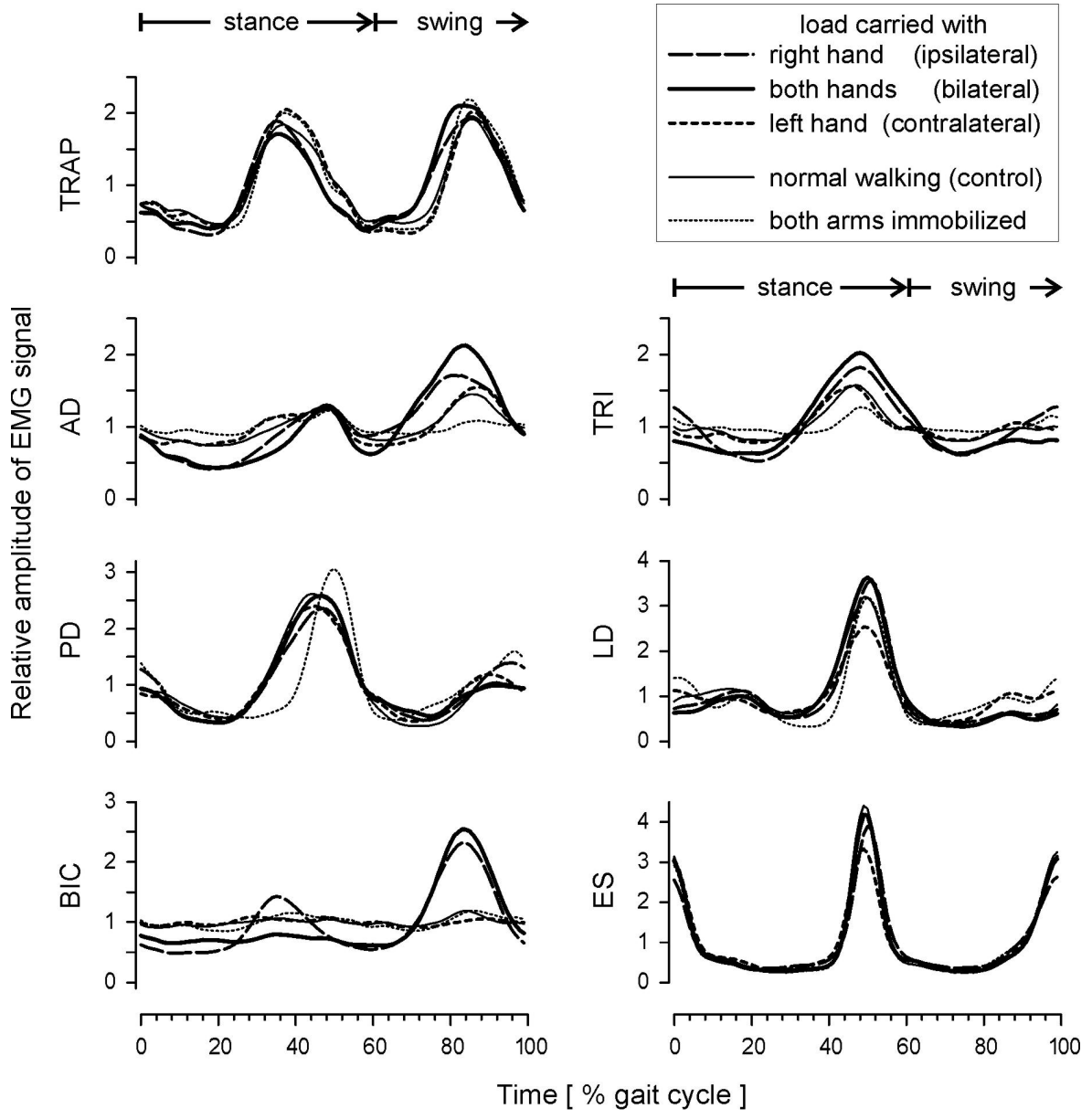

Figure 2. Superimposed EMG curves of the five gait conditions. These ensemble averaged EMG curves represent the mean activation waveforms (i.e. the group averages of all 20 participants) of each muscle in each gait condition. The EMG voltage of each muscle has been rescaled by dividing it by the mean value of the respective condition (see methods), resulting in average amplitude of 1 for all conditions and muscles. Stance and swing phases of the right leg are indicated.

\section{RESULTS}

Ensemble averaged EMG curves (group results) of the five gait conditions are superimposed in Figure 2. The temporal EMG patterns were similar and consistent across conditions, although swinging movements of the loaded arm were diminished during load carriage, and although arm movements were prevented by the brace in the immobilization condition (Figure 1). The EMG peak of the posterior deltoid (PD) in the middle of the gait cycle was somewhat narrower in the arm immobilization condition than in the other walking conditions. Moreover, the EMG curves of the biceps brachii (BIC) had marked maxima during bilateral and ipsilateral load carriage (by the right hand), but showed little modulation in the other conditions.

From the EMG data of the seven muscles, PCA extracted two factors with eigenvalues greater than unity $(A, B)$ for each condition. Figure 3 illustrates the respective factor scores $A$ and $B$, i.e. the basic temporal activation components. The factor scores $A$ of the five conditions were strongly correlated, with correlation coefficients $r$ ranging 
between 0.87 and 0.99 . Likewise, the factor scores B were correlated, with coefficients ranging between 0.89 and 0.94 . Basic temporal activation components denote typical bursts of EMG activity at certain moments of gait cycle. The factor loadings (Figure 3) indicate how a given component is allocated to different muscles. Component $A$ denotes biphasic activity with peaks around $35 \%$ and $85 \%$ of the gait cycle, i.e. in the mid-stance phases of either leg. Muscles loading highly on this component were TRAP, AD and BIC. Factor score B involves peak activation at contralateral heel strike (50\% of the gait cycle) and a smaller peak at the onset of the gait cycle (at ipsilateral heel strike). This pattern is typical for EMGs of the PD, TRI, LD and ES, as the factor loadings indicate.
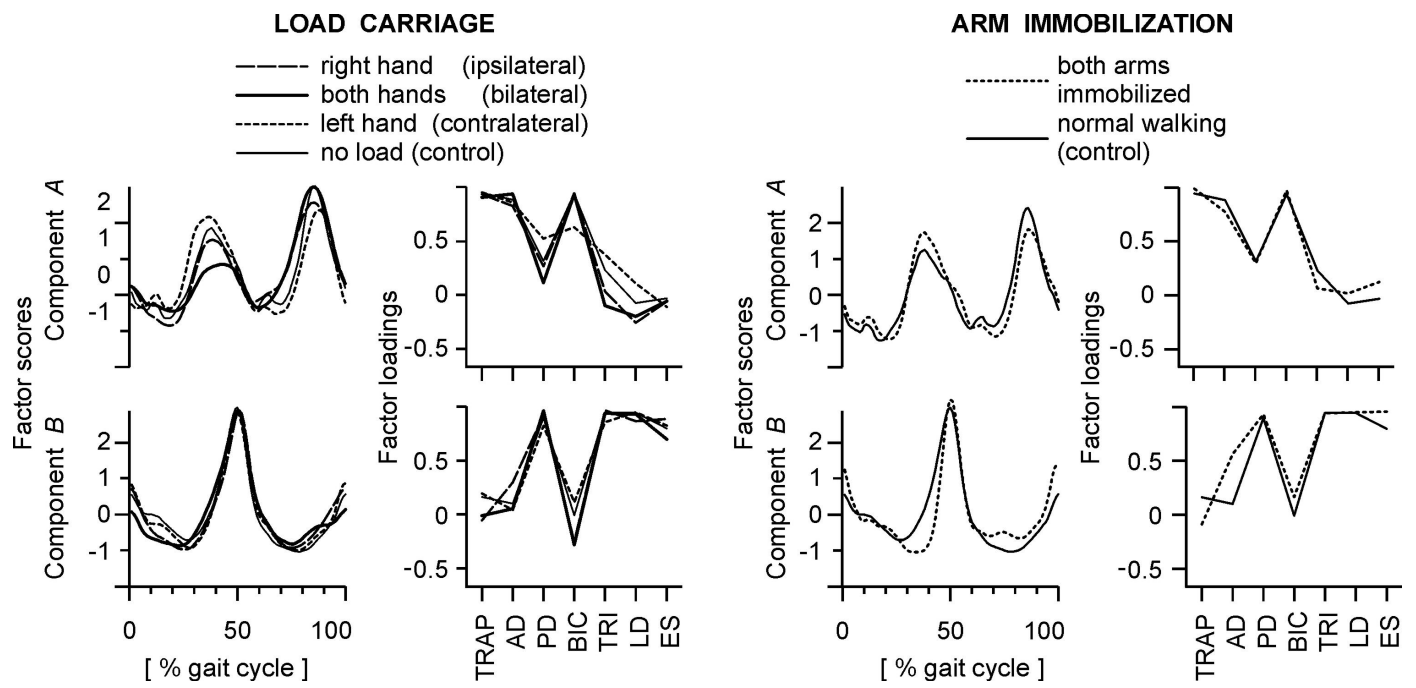

Figure 3. Basic temporal muscle activation patterns in the five gait conditions. Factor scores: From the EMG curves of each gait condition, two temporal activation components $A$ and $B$ (factor scores) with eigenvalues greater than unity were derived by principal component analysis (PCA). The factor scores of the various conditions are superimposed for comparison. Factor loadings (weighting coefficients) indicate how a given factor score is allocated to the different muscles.

Despite the similar temporal activation patterns, the amount of muscle activity differed significantly between conditions. Table 1 lists the respective EMG activity levels (normalized to MVC values) and their relative changes, compared to the baseline condition of normal walking. When the load was carried with the right hand (ipsilateral to muscles studied), the EMG activity of TRAP, AD, PD, BIC and TRI increased to values $\sim 250 \%$ above baseline. Activity of the same muscles increased less during bilateral bimanual load carriage, reaching values $\sim 150 \%$ above baseline. However, the right ES and LD were less active during unimanual carriage of the entire load (10\% of body weight) by the ipsilateral hand than during bimanual carriage of two smaller loads ( $2 \times 5 \%$ of body weight). Muscles on the non-loaded side were involved, too. When the load was carried by the left hand, mean EMG activations of the right TRAP, AD, PD, TRI, LD and ES increased significantly (by $\sim 50 \%$ ) above baseline values. Statistical comparison of the non-normalized EMG voltage levels yielded analogous results (not shown for sake of brevity).

Gender-dependent differences of the EMG amplitudes were found for bimanual load carriage. Mean AD activity was higher $(p<0.05)$ in women $(3.05 \% \mathrm{MVC})$ than in men (1.36 \% MVC), and also TRI activity differed significantly (women: $4.7 \%$ MVC; men: $2.8 \%$ MVC). 
Brazilian Journal of Motor Behavior

Table 1 - EMG activity levels during normal forward walking, load carriage, and arm immobilization conditions

\begin{tabular}{|c|c|c|c|c|c|c|}
\hline $\begin{array}{l}\text { Muscle } \\
\text { (right side) }\end{array}$ & & $\begin{array}{l}\text { Normal } \\
\text { walking }\end{array}$ & $\begin{array}{l}\text { Load in right hand } \\
\text { (ipsilateral) }\end{array}$ & $\begin{array}{l}\text { Loads in both } \\
\text { hands (bilateral) }\end{array}$ & $\begin{array}{l}\text { Load in left hand } \\
\text { (contralateral) }\end{array}$ & $\begin{array}{l}\text { Walking with } \\
\text { immobilized arms }\end{array}$ \\
\hline TRAP & $\begin{array}{l}\text { EMG amp. } \\
\% \text { change }\end{array}$ & $\begin{array}{l}3.53 \pm 1.85 \\
=100 \%\end{array}$ & $\begin{array}{l}11.5 \pm 4.91 * * \\
+265 \pm 173 \%\end{array}$ & $\begin{array}{r}8.22 \pm 3.533^{* *} \# \\
+153 \pm 99 \%\end{array}$ & $\begin{array}{r}5.97 \pm 2.56 \text { ** } \\
+80 \pm 48 \%\end{array}$ & $\begin{array}{r}3.31 \pm 1.53 \\
+2 \pm 56 \%\end{array}$ \\
\hline$A D$ & $\begin{array}{l}\text { EMG amp. } \\
\% \text { change }\end{array}$ & $\begin{array}{l}0.81 \pm 0.42 \\
=100 \%\end{array}$ & $\begin{array}{l}3.76 \pm 3.5^{* *} \\
+392 \pm 467 \%\end{array}$ & $\begin{array}{r}2.20 \pm 1.444^{* *} \# \\
+188 \pm 181 \%\end{array}$ & $\begin{array}{r}1.31 \pm 0.86 \text { ** } \\
+67 \pm 57 \%\end{array}$ & $\begin{array}{r}0.55 \pm 0.21^{*} \\
-23 \pm 25 \%\end{array}$ \\
\hline PD & $\begin{array}{l}\text { EMG amp. } \\
\% \text { change }\end{array}$ & $\begin{array}{l}2.48 \pm 0.98 \\
=100 \%\end{array}$ & $\begin{array}{l}7.65 \pm 5.17 \text { ** } \\
+204 \pm 164 \%\end{array}$ & $\begin{array}{r}4.95 \pm 2.16^{* *} \# \\
+101 \pm 53 \%\end{array}$ & $\begin{array}{r}3.16 \pm 1.344^{* *} \\
+30 \pm 36 \%\end{array}$ & $\begin{array}{r}1.19 \pm 0.62 \text { ** } \\
-49 \pm 23 \%\end{array}$ \\
\hline $\mathrm{BIC}$ & $\begin{array}{l}\text { EMG amp. } \\
\% \text { change }\end{array}$ & $\begin{array}{l}0.63 \pm 0.22 \\
=100 \%\end{array}$ & $\begin{array}{l}2.14 \pm 1.14 \text { ** } \\
+234 \pm 119 \%\end{array}$ & $\begin{array}{r}1.63 \pm 1.01 \text { ** \# } \\
+143 \pm 99 \%\end{array}$ & $\begin{aligned} 0.68 & \pm 0.25 \\
& +7 \pm 13 \%\end{aligned}$ & $\begin{array}{r}0.68 \pm 0.28 \\
+9 \pm 29 \%\end{array}$ \\
\hline TRI & $\begin{array}{l}\text { EMG amp. } \\
\% \text { change }\end{array}$ & $\begin{array}{l}1.49 \pm 0.91 \\
=100 \%\end{array}$ & $\begin{array}{l}4.65 \pm 2.79 * * \\
+235 \pm 204 \%\end{array}$ & $\begin{array}{r}3.77 \pm 1.96 * * \\
+166 \pm 115 \%\end{array}$ & $\begin{array}{r}1.91 \pm 1.11 \text { ** } \\
+33 \pm 36 \%\end{array}$ & $\begin{array}{r}1.26 \pm 0.75 \text { * } \\
-13 \pm 21 \%\end{array}$ \\
\hline LD & $\begin{array}{l}\text { EMG amp. } \\
\% \text { change }\end{array}$ & $\begin{array}{l}3.31 \pm 1.41 \\
=100 \%\end{array}$ & $\begin{aligned} 3.41 \pm & 1.97 \\
& +2 \pm 32 \%\end{aligned}$ & $\begin{array}{r}4.32 \pm 2.19^{* *} \# \\
+30 \pm 32 \%\end{array}$ & $\begin{array}{r}4.25 \pm 2.31^{* *} \\
+30 \pm 44 \%\end{array}$ & $\begin{array}{r}4.28 \pm 1.91 \text { ** } \\
+38 \pm 50 \%\end{array}$ \\
\hline ES & $\begin{array}{l}\text { EMG amp. } \\
\% \text { change }\end{array}$ & $\begin{array}{l}7.19 \pm 2.52 \\
=100 \%\end{array}$ & $\begin{array}{r}6.44 \pm 2.92 \\
-8 \pm 36 \%\end{array}$ & $\begin{aligned} 8.27 & \pm 2.82^{* *} \# \\
& +17 \pm 15 \%\end{aligned}$ & $\begin{array}{r}11.79 \pm 3.21^{* *} \\
+69 \pm 21 \%\end{array}$ & $\begin{array}{l}8.81 \pm 3.56 \text { ** } \\
+22 \pm 13 \%\end{array}$ \\
\hline
\end{tabular}

Mean EMG levels, averaged over the entire gait cycle. Amplitudes are normalized to maximum voluntary contractions [unit \% MVC]. Numbers represent inter-individual mean \pm standard deviation. \% change: EMG activity of normal walking (no load) was set to $100 \%$ (baseline) to calculate relative changes for the other conditions.

${ }^{*}$ Significantly different from normal walking (baseline): ${ }^{*} p<0.05,{ }^{* *} p<0.01$ (paired t-tests).

\# Significant difference between unimanual ipsilateral (right hand) load carriage and bimanual load carriage: \# $p<0.05$ (paired t-test).

Walking with immobilized arms involved decreased EMG activity of triceps brachii (TRI) and deltoid (AD, PD) muscles, with lower amplitudes than in the baseline condition of normal gait (Table 1). By contrast, LD and lumbar ES were somewhat more ( 25\%) active in the arm immobilization condition than during normal walking. The participants were not aware of the remaining rhythmic arm and shoulder muscle activity when walking with immobilized arms. When we showed them their EMG data after the experiment, they were often astonished about the rhythmical EMG bursts of their arm and shoulder muscles in this condition.

\section{DISCUSSION}

The purpose of the present study was to identify common temporal activation patterns of upper limb muscles for different conditions of human walking. We recorded EMG signals of arm and shoulder muscles during treadmill walking with normal arm swing, during walking without arm swing (arms immobilized), and during walking while carrying loads by hand (unilaterally and bilaterally). Gait velocity was kept constant at $6 \mathrm{~km} / \mathrm{h}$. As a main result, PCA showed that the different gait conditions involved two nearly identical basic temporal activation components (factor scores A, B), which characterized the EMG waveforms of the seven investigated muscles. Hence the basic neuromuscular synergies remained stable across gait conditions, although the arm movements differed markedly. TRAP, AD and BIC showed biphasic activity (factor score A) with peaks around mid-stance. The TRAP controls inclination of the shoulder girdle in the frontal plane and shoulder abduction ${ }^{14}$, so that the arms clear the trunk and swing mostly in anterior-posterior direction during normal walking. $A D$ and $B I C$ contractions support forward arm swing (shoulder flexion) in the stance phase, and oppose backward arm swing (shoulder

\begin{tabular}{l|l|l|l}
\hline $\begin{array}{l}\text { Kuhtz-Buschbeck \& } \\
\text { Frendel }\end{array}$ & 2015 & VOL. 9 & N.1 \\
\end{tabular}


extension) in the swing phase of the ipsilateral leg. ${ }^{6}$ Activation peaks of shoulder extensor muscles (PD, TRI, LD) around contralateral heel strike (factor score B) influence the reversal from forward to backward arm swing during normal walking. ${ }^{6}$ Concomitant ES contractions control trunk movements during weight transfer in the double support phase. ${ }^{14,15}$

Common temporal activation patterns, which remain consistent in different modes of gait, represent an effective motor control strategy. ${ }^{7,8,9}$ Ivanenko and collaborators ${ }^{13,16}$ found that five basic temporal activation components account for most of the EMG activity of 32 leg and trunk muscles during treadmill walking at different velocities with and without body weight support. Factor score $A$ of the present study aligns with temporal components 2 and 5 described by Ivanenko et al., see their Figure $2 .{ }^{16}$ Their component 2 is synchronized with ankle extensor activation and propulsion in the terminal stance phase of walking, and their component 5 is synchronized with deceleration of the leg (hamstrings) and ankle dorsiflexion (tibialis anterior) in the late swing phase. The peak of component $B$, as found in the present study, corresponds to component 3 described by Ivanenko and colleagues ${ }^{16}$, and is synchronized with trunk muscle activation in the middle of the gait cycle.

The persistent rhythmical activity of the deltoid and other upper arm muscles during walking with immobilized shoulder and elbow joints implies that lower and upper limb muscle activations are coupled during human gait. ${ }^{17,18}$ A central motor program, which excites motor neurons of leg and arm muscles conjointly during walking, may be generated by a spinal neuronal network, as known from neurophysiological research on locomotion of quadrupedal animals.19,20 Although we demonstrated that walking without arm swing involves temporal activation patterns similar to normal gait, the EMG signals of $A D, P D, T R I$ were clearly diminished, and the PD activation peak was shortened in the immobilization condition. Probably the activity of these muscles is influenced by proprioceptive feedback from the moving upper limbs during natural gait with unrestricted arm swing. Persistent LD and ES activity in the immobilization condition may be related to spine movements, which were not obstructed. Indeed, LD and lumbar ES were more active in the arm immobilization condition than during normal walking. Previous research showed that compressive loading of inter-vertebral joints is augmented during walking without arm swing. ${ }^{21}$

The EMG activity of right upper arm and shoulder muscles just about tripled when a load was carried by the ipsilateral hand, and doubled when the same load was evenly allocated to both hands. Enhanced paravertebral muscle activity (lumbar ES) on the nonloaded side will resist lateral bending of the spine towards the side of the load. ${ }^{22}$ Donker and colleagues reported augmented movement amplitudes and enhanced deltoid muscle activity of the non-loaded free arm when test persons walked with a weight attached to the wrist of the other arm. ${ }^{23,24}$ The present data add to their findings by demonstrating additional increases of TRAP, AD, PD, TRI and LD EMG signals on the non-loaded side during unimanual load carriage. Although the amount of EMG activity varied markedly, the present data show that the basic temporal patterns of upper limb muscle activation remain stable across walking conditions with and without load carriage.

The present study was not without limitations. Only seven EMG channels were available, and kinematic data could not be recorded simultaneously due to technical constraints. However, kinematic and kinetic data of arm swing during human walking have been published elsewhere. $1,3,4$ We used a treadmill for practical reasons (constant gait 
velocity; no EMG telemetry available). It is known that arm-leg coordination may differ to some extent between ground and treadmill walking. ${ }^{25}$ Future research on upper limb EMG activity during human locomotion may include more muscles and provide supplementary kinematic and kinetic data, and might also clarify possible differences of EMG patterns between ground and treadmill locomotion.

\section{REFERENCES}

1. Collins SH, Adamczyk PG, Kuo AD. Dynamic arm swinging in human walking. Proc R Soc Lond B Biol Sci 2009; 276: 3679-88.

2. Meyns $P$, Bruijn SM, Duysens J. The how and why of arm swing during human walking. Gait Posture 2013; 38: 555-62.

3. Pontzer H, Holloway JH, Raichlen DA, Lieberman DE. Control and function of arm swing in human walking and running. J Exp Biol 2009; 212: 523-34.

4. Goudriaan M, Jonkers I, van Dieen JH, Bruijn SM. Arm swing in human walking: What is their drive? Gait Posture 2014; 40: 321-26.

5. Ballesteros $M$, Buchthal $F$, Rosenfalck $P$. The pattern of muscular activity during arm swing of natural walking. Acta Physiol Scand 1965; 63: 296-310.

6. Kuhtz-Buschbeck JP, Jing B. Activity of upper limb muscles during human walking. J Electromyogr Kinesiol 2012; 22: 199-206.

7. Lacquaniti F, Ivanenko YP, Zago M. Patterned control of human locomotion. J Physiol 2012; 590: 2189-99.

8. Zelik KE, La Scaleia V, Ivanenko YP, Lacquaniti F. Can modular strategies simplify neural control of multidirectional human locomotion? J Neurophysiol 2014; 111: 1686-1702.

9. Ivanenko YP, Poppele RE, Lacquaniti F. Distributed neural networks for control-ling human locomotion. Lessons from normal and SCl subjects. Brain Res Bull 2009; 78: 13-21.

10. Hermens HJ, Freriks B, Disselhorst-Klug C, Rau G. Development of recommendations for SEMG sensors and sensor placement procedures. J Electromyogr Kinesiol 2000; 10: 36174.

11. Burden A. How should we normalize electromyograms obtained from healthy participants? What we have learned from over 25 years of research. J Electromyogr Kinesiol 2010; 20: 1023-35.

12. Chau T. A review of analytical techniques for gait data. Part 1: Fuzzy, statistical and fractal methods. Gait Posture 2001; 13: 49-66.

13. Ivanenko YP, Poppele RE, Lacquaniti F. Five basic muscle activation patterns account for muscle activity during human locomotion. J Physiol 2004; 556: 267-82.

14. Ceccato JC, de Sèze M, Azevedo C, Cazalets JR. Comparison of trunk activity during gait initiation and walking in humans. PLoS ONE 2009; 4: e8193.

15. Anders C, Wagner H, Puta C, Grassme R, Petrovitch A, Scholle HC. Trunk muscle activation patterns during walking at different speeds. J Electromyogr Kinesiol 2007; 17: 245-52. 
16. Ivanenko YP, Cappellini G, Poppele RE, Lacquaniti F. Spatiotemporal organization of alpha-motoneuron activity in the human spinal cord during different gaits and gait transitions. Eur J Neurosci 2008; 27: 3351-68.

17. Sylos-Labini F, Ivanenko YP, MacLellan MJ, Cappellini G, Poppele RE, Lacquaniti F. Locomotor-like leg movements evoked by rhythmic arm movements in humans. PLoS ONE 2014; 9(3): e90775.

18. Zehr EP, Duysens J. Regulation of arm and leg movement during human locomotion. Neuroscientist 2004; 10: 347-61.

19. Dietz V, Michel J. Human bipeds use quadrupedal coordination during locomotion. Ann N Y Acad Sci 2009; 1164: 97-103.

20. Falgairolle M, de Sèze M, Juvin L, Morin D, Cazalets JR. Coordinated network functioning in the spinal cord: an evolutionary perspective. J Physiol (Paris) 2006; 100: 304-16.

21. Callaghan JP, Patla AE, McGill SM. Low back three-dimensional joint forces, kinematics, and kinetics during walking. Clin Biomech (Bristol) 1999; 14: 203-16.

22. McGill SM, Marshall L, Andersen J. Low back loads while walking and carrying: comparing the load carried in one hand or in both hands. Ergonomics 2013; 56: 293-302.

23. Donker SF, Mulder T, Nienhuis B, Duysens J. Adaptation in arm movements for added mass to wrist or ankle during walking. Exp Brain Res 2002; 145: 26-31.

24. Donker SF, Daffertshofer A, Beek PJ. Effects of velocity and limb loading on the coordination between limb movements during walking. J Mot Behav 2005; 37: 217-30.

25. Carpinella I, Crenna P, Rabuffetti M, Ferrarin M. Coordination between upper- and lowerlimb movements is different during overground and treadmill walking. Eur J Appl Physiol 2010; 108: 71-82.

Citation: Kuhtz-Buschbeck JP, Frendel A Stable patterns of upper limb muscle activation in different conditions of human walking. BJMB. 2015: 9(1): 1-10.

Editor: Joao A. C. Barros, California State University Fullerton, Fullerton, CA, USA.

Copyright: (C) 2015 Kuhtz-Buschbeck and Frendel and BJMB. This is an open-access article distributed under the terms of the Creative Commons Attribution-NonCommercial-NoDerivatives 4.0 International License which permits unrestricted use, distribution, and reproduction in any medium, provided the original author and source are credited.

Funding: There was no funding for this study. Sanitätshaus Assmann (Kiel, Germany) donated the brace (mediArmfix® shoulder immobilization support, Bayreuth, Germany).

Competing interests: The authors have declared that no competing interests exist.

Download: http://socibracom.com/bjmb/index.php/bjmb/issue/view/10 